\title{
Content-specific pedagogical knowledge, practices, and beliefs underlying the design of physics lessons: A case study
}

\author{
Shulamit Kapon ${ }^{1, *}$ and Avraham Merzel $^{2}$ \\ ${ }^{1}$ Faculty of Education in Science and Technology, \\ Technion-Israel Institute of Technology, Haifa 3200003, Israel \\ ${ }^{2}$ The Seymour Fox School of Education, The Hebrew University of Jerusalem, \\ Mt. Scopus 9190501, Jerusalem, Israel
}

(Received 22 June 2018; published 3 May 2019)

\begin{abstract}
We present an analysis of the in situ support provided to preservice physics teachers (PPTs) enrolled in a Methods for Teaching Physics course $(N=28)$ at a research university, while working on the design of 20 lessons in mechanics and waves they taught later in the course. The PPTs submitted 4 evolving plans for each lesson, and received guidance and support in two consecutive consultation meetings on each lesson plan (30 min each), as well as written feedback via the course website. Using grounded theory methods, the analysis examines the interactions between instructors and preservice teachers over the evolving lesson plans as captured in the videos of the consultation meetings and written correspondence. We analyze the PPT-initiated and instructor-initiated concerns, guidance, and support to infer and unpack tacit professional knowledge, practices, and beliefs. The emergent categorization articulates the knowledge, practices, and beliefs that inform and guide the design of physics lessons that offer in-depth treatment of concepts, procedures, practices, and epistemological aspects of physics in an engaging and meaningful way for students, and foster active learning. The extent to which these categories are grounded in the discipline is discussed.
\end{abstract}

DOI: 10.1103/PhysRevPhysEducRes.15.010125

\section{INTRODUCTION}

"You think you know the material you are going to teach, and then you start to prepare the lesson. Well, soon enough you start thinking about the things (you want to teach). And after a while when you have rethought everything, and you think "now I understand how to do it," you come to class. You face hurdles and challenges that you did not foresee. I mean, even when writing the lesson plan, you think about your peers and high school students who will experience the lesson as learners, how they will react. You realize that you have to think again and again and again about how to take that thing that you took for granted that you would be able to teach, how to take it and turn it into a lesson, turn it into something that will make the other party (i.e., the students) learn. You, yes, let's say that ... without that experience, without learning (in the physics teacher education program) I would not have been able to make

\footnotetext{
*skapon@technion.ac.il
}

Published by the American Physical Society under the terms of the Creative Commons Attribution 4.0 International license. Further distribution of this work must maintain attribution to the author(s) and the published article's title, journal citation, and DOI. this distinction between knowing the discipline and knowing how to teach the discipline. Studying here helped me see this difference."

Tomer (pseudonym), a senior student in the physics teacher education program at the Technion.

Knowing the discipline and knowing how to teach the discipline are different types of expertise. While there is vast consensus that the former is a prerequisite for the latter, teacher educators have been grappling for more than four decades with how to develop, nurture, and assess teachers' ability to teach a discipline in a deep, engaging, and meaningful way. Fostering the development of this capacity in preservice teacher education is still considered an unresolved challenge $[1,2]$. The main efforts at addressing this challenge have been targeted at articulating the structure and components of professional knowledge for teaching, and, more recently, the core practices involved. The current work aims to contribute to this scholarship in the context of physics education.

\section{A. Conceptual framework}

In the mid-1980s Shulman [3] suggested that the professional knowledge of expert teachers is composed of three components: (i) Content knowledge-the amount and organization of knowledge per se in the mind of the teacher; (ii) pedagogical content knowledge (PCK)—ways of representing and formulating the topic by making it 
comprehensible to others, Shulman included knowledge of students' conceptions and misconceptions in this category as well; (iii) curricular knowledge-the full range of available learning materials designed for the teaching of particular topics at a given level, and the contraindications for their use.

Building on this model, Grossman [4] suggested that expert teachers are characterized not only by their professional knowledge, but also by their professional beliefs. She envisioned Shulman's PCK as pedagogical content knowledge and beliefs, and suggested that it is influenced by three categories of knowledge and beliefs that teachers develop throughout the course of their careers: (i) Subjectmatter knowledge and beliefs which Grossman divided into (a) substantive knowledge and beliefs that covers the knowledge and beliefs related to important concepts and skills, and (b) syntactic knowledge and beliefs that covers the knowledge and beliefs related to knowing how the concepts and skills are structured and organized in the discipline; i.e., the epistemological nature of the discipline; (ii) Pedagogical knowledge and beliefs; namely, the knowledge and beliefs related to classroom management, instructional principles, learners and learning, and educational aims. (iii) Knowledge and beliefs about context; namely, the knowledge and beliefs related to the community, students, school, and district. Note that although these latter two categories influence teachers' pedagogical content knowledge and beliefs, the model may be interpreted as something that can be initially learned in teacher education programs in a generic way that is unrelated to specific subject matter.

A decade later, a group of teacher educators who were specifically studying the PCK of science teachers [5] defined beliefs in the PCK of science teachers which they conceptualized as an orientation towards science teaching that reflects how a teacher views the goal of science teaching. Examples of different orientations include representing a particular body of knowledge, facilitating active and handson learning, providing opportunities for the students to discover the target concepts and ideas, etc. They argued that a teacher's orientation towards science teaching is shaped by four domains of knowledge: (i) Knowledge of science curricula which covers familiarity with specific curriculum materials, as well as knowledge about the goals and objectives of teaching science; (ii) knowledge of students' understanding of science which covers knowledge and beliefs about the prerequisite knowledge for learning specific topics, and areas of students' difficulty; (iii) knowledge of instructional strategies which covers a general approach to science instruction as well as topic-specific effective instructional representations (effective analogies, examples, etc.) and activities that can help students comprehend the specific content and spark their interest; (4) knowledge of assessment of scientific literacy which covers those aspects of students' learning that should be assessed, and relevant methods for assessing them. Note that the epistemological nature of the discipline is not considered as knowledge in this model. Thus, while the model explicitly discusses orientations towards science teaching, it does not explicitly differentiate between scientific disciplines (i.e., biology, physics, chemistry). The specific notion of teacher orientation towards science teaching was critiqued for its ambiguity; however, and further theoretical and empirical work was recommended [6].

Ball and colleagues further elaborated on Shulman's subject matter knowledge and pedagogical content knowledge in a way that emphasized the nature of the discipline that is being taught (in their case, mathematics) [7]. Shulman's category of subject matter knowledge was conceptualized as composed of (i) common content knowledge made up of the mathematical knowledge shared with others who know and use mathematics; (ii) horizon content knowledge, covering awareness of how mathematical topics are related over the span of mathematics included in the curriculum; (iii) specialized content knowledge, referring to mathematical knowledge not typically needed for purposes other than teaching. The latter category, as the authors described it, corresponds closely in our view to Grossman's notion of syntactic content knowledge: "Teachers, however, must hold unpacked mathematical knowledge because teaching involves making features of particular content visible to and learnable by students. Teaching about place value, for example, requires understanding the place-value system in a self-conscious way that goes beyond the kind of tacit understanding of place value needed by most people." [7]. In Ball's model PCK was conceptualized as composed of (i) knowledge of content and student covering knowledge about what students are likely to think with regard to the topic in question, and what they may find confusing; (ii) knowledge of content and teaching, covering knowledge of how to evaluate the instructional advantages and disadvantages of examples and representations for particular instructional goals; (iii) knowledge of content and curriculum, defined as familiarity with a variety of curricular materials. A strong attribute of this model, in our view, is the way it grounds teachers' knowledge in the discipline they teach. However, it disregards the effect of teachers' beliefs and opinions on their practice, which has been shown to affect their practice considerably [8].

While there is no consensus on a specific model of PCK, there is a broad consensus on Shulman's general idea that pedagogical content knowledge distinguishes the content specialist from the content pedagogue and that PCK develops as teachers of a specific discipline transform their content knowledge for the purposes of teaching $[9,10]$. Thus, the PCK of experienced teachers is far more developed than the PCK of novice teachers [11], and teachers' well-developed PCK leads to better learning in their students [12]. 
Recent reviews and position papers on preservice and novice science teachers' knowledge has focused on what teachers' need to know rather than adhering to a specific model of this knowledge $[13,14]$. However, some of the most prominent scholars who have contributed to theoretical conceptualizations of the knowledge required for teaching and its implications for teacher education now argue that the structure of teacher education should be changed and reorganized. Instead of organizing the teacher education curriculum around the different kinds of knowledge teachers should learn, they suggest organizing it around core practices, in which knowledge, skills, and emerging professional identity develop through the process of learning to practice as good teachers $[2,15]$. These researchers have thus not only called for a change in the curriculum of teacher education programs, but also in the pedagogies employed [16]. However, most related work has been done in the domain of literacy and mathematics education and the elementary school level. Even there, researchers tend to emphasize grounding in the discipline that is being taught: "Among the features that are likely to distinguish the next generation of practice-oriented teacher education pedagogies is the integration of subject-matter knowledge for teaching and the capacity for discretionary adaptation and judgment with discrete behaviors and actions." [2]. Physics education researchers have been calling for disciplinary-based teacher education for the last three decades [17-20], and debates about refocusing teacher education program on what teachers do rather than what teachers have to know are beginning to appear in this literature as well [8].

\section{B. The current study}

In 2016 we redesigned the course titled Methods for Teaching Physics 1 at the Technion-Israel Institute of Technology. The course was restructured as a project-based learning environment in which the projects the prospective teachers worked on were the design and teaching of physics lessons [21]. We present an analysis of the in situ support provided to all the preservice physics teachers (PPTs) enrolled in the course $(N=28)$ while they were working on the design of the lessons they were planning to teach; i.e., while they were engaged in the central practice of planning a lesson (20 lessons). The analysis aims at uncovering the nature, structure, and scope of the specialized knowledge, practices, and beliefs that were brought into the open and articulated during these iterative structured interactions between the preservice teachers and the instructors on the evolving lesson plans.

Our use of the term "bring into the open" is taken from the literature on cognitive apprenticeship [22], since our working hypothesis is that the underlying knowledge and beliefs that shape the practice of expert teachers are tacit, and if we want novice teachers to learn them through practice, they should be externalized. It is impossible to teach everything in one course. Thus, the scope and content of specialized knowledge, practices, and beliefs that were brought into the open and articulated in the interactions between the instructors and the preservice teachers are limited to the goals and scope of the course. Methods for Teaching Physics 1 focuses on the instruction and learning of mechanics and waves at the K-12 level. Special attention is given to conceptual clarity, problem solving, and active and meaningful learning. The course does not specifically deal with aspects of scientific inquiry and argumentation since these are the prime focus of a different course in the program. Furthermore, the instructors' perception of what counts as high quality physics teaching, and in the context of this study, what counts as a good physics lesson in particular, influenced their professional vision [23] considerably, and thus shaped the interactions between the instructors and the preservice teachers regarding the evolving lesson plans. Specifically, we (i.e., instructors and authors) consider "good physics lessons" to be lessons that provide in-depth treatment of concepts, procedures, practices, and epistemological aspects of physics, that do so in an engaging and meaningful way for the students, while fostering active learning.

The paper aims to answer the following research questions:

(1) What elements of knowledge, practices, and beliefs were brought into the open and articulated, while the instructors guided and supported the preservice teachers in the design of the physics lessons that the preservice teachers were asked to teach during the course?

(2) To what extent were these elements grounded in the discipline?

\section{The significance of the study}

Etkina and colleagues have argued that physics teachers need preparation in how to teach specific physics topics, and that methods courses teaching generic "science" cannot provide this preparation $[8,19,24]$. This work provides further empirical support to this claim. The physics teacher preparation program at the Technion [25] offers five different disciplinary-based educational courses for preservice teachers in addition to the general education courses. It shares many of the core principles that underlie Etkina's approach to teacher education, such as cognitive apprenticeship, scaffolding, active learning, and microteaching (i.e., sessions in which preservice teachers teach their peers $[19,26,27])$. However, the design of the course in which we carried out this study diverges from Etkina's methods for teaching courses in the following respects: (i) The main scientific and pedagogical content covered in our course was encompassed by the span of the projects the preservice teachers were working on. Hence, microteaching did not only serve as a venue for our students to practice teaching, but also for modeling to their peers the 


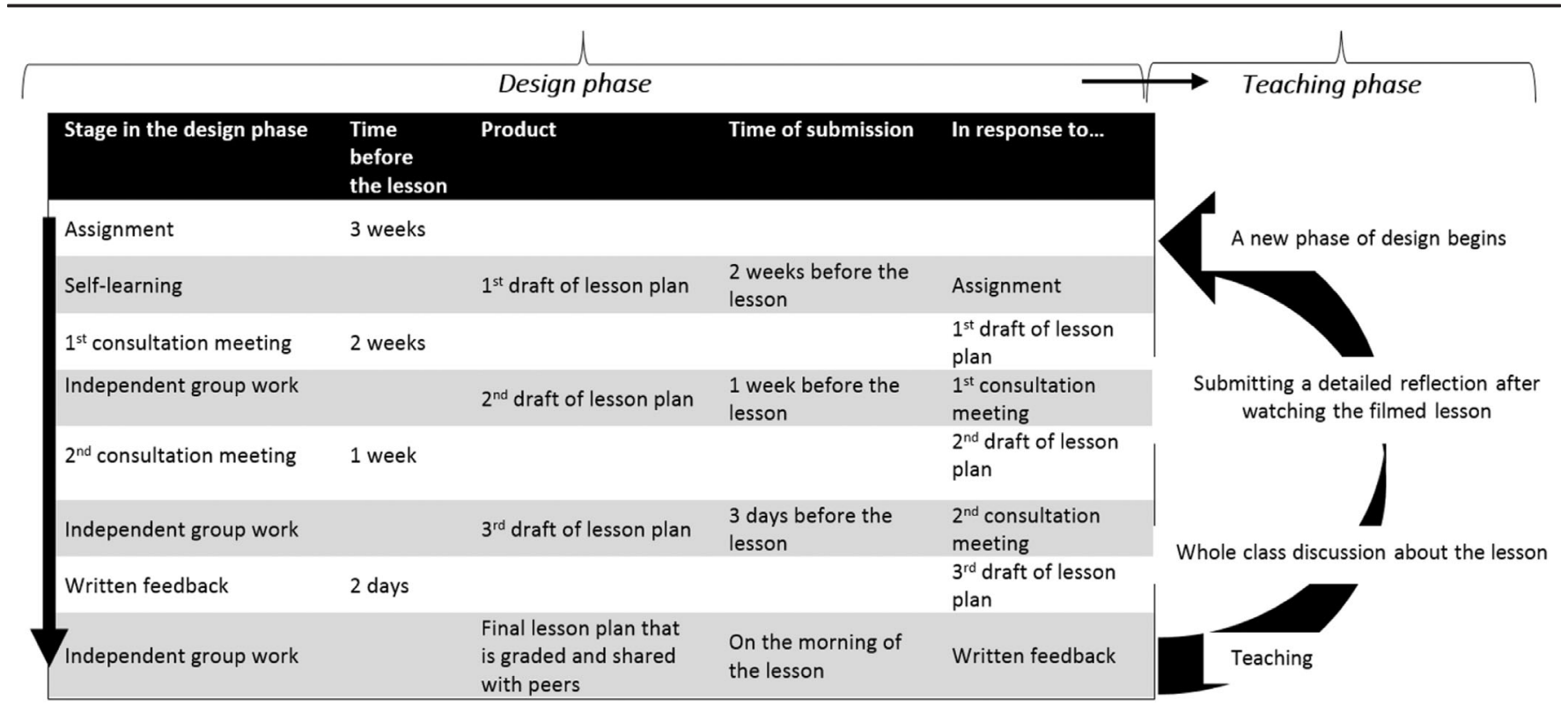

FIG. 1. The structure of a full project. Reproduced from Fig. 1 in Ref. [21].

pedagogies and methods for teaching the course aims to teach. The extensive support the instructors provided during each lesson design aimed to bring the lessons to this level [21]. (ii) We deliberately do not focus in this course on one curriculum intended for the instruction of mechanics and waves at the upper secondary level. We intentionally expose the preservice teachers to different curricular materials, and specifically engage them in figuring out their affordances and constraints for different instructional goals. Thus, the empirical work presented in this paper was carried out in different contextual settings, and employed very different research methods, as elaborated below. While limited solely to the design of a lesson plan, and situated within a particular methods for teaching physics course, to the best of our knowledge, this is the first attempt to suggest a model of professional knowledge, practices, and beliefs about teaching that is specifically grounded in the instruction of physics.

Previous empirical attempts to elicit teachers' PCK and articulate its form and structure have mainly employed two methodological approaches [28]: (i) examining the teaching of novice and experienced teachers, and often interviewing these individuals after the observation to better understand the reasoning behind specific pedagogical decisions and moves; (ii) examining the way novice and experienced teachers analyze video recording of lessons (their own or others'). The current work differs from these in that its main source of data derives from the analysis of authentic lesson designs and the in situ interactions between preservice teachers and their instructors during the support provided to them as they worked on their designs. In so doing it provides a further articulation of the notion of professional knowledge for teaching physics. Although practice-based teacher education is constantly being advocated, very little is known about how the engagement of prospective teachers in authentic practice can be facilitated in a way that externalizes the many facets of professional knowledge devolved to teaching that we want them to learn. This study shows how thoughtfully guided design of lessons can support this goal.

\section{EDUCATIONAL CONTEXT}

The data were collected in the course Methods for Teaching Physics 1 that we redesigned. The course aims to teach the didactics and pedagogy specifically related to the instruction of mechanics and waves at the middle and upper secondary levels, and focuses on conceptual clarity, problem solving, and active and meaningful learning. The course took place in a research university (Technion), as part of the mandatory curriculum for a teaching certificate in physics at the high school level. It lasted 13 weeks and consisted of two weekly sessions of 90 minutes each. The first author was the lecturer in the course and initiated the redesign of the course as a project-based learning environment. The second author joined the research group as a postdoc. He was the teaching assistant in the course, took part in its redesign, and his main research focus was the learning of the preservice physics teachers. Both authors are experienced in-service (2nd author) and former (1st author) high school physics teachers, and in practice, the course was co-taught by both, although each focused on different aspects. When discussing the interactions with the preservice teachers enrolled in the course, we refer to us both as the "instructors" and the preservice physics teachers as the "PPTs".

By conceptualizing the design and teaching of an effective lesson as a complex task with many possible 
solutions that could be defined as a small project, we constructed the course as a form of a project-based learning environment [29]. The course was structured as a workshop in which groups of 2-3 PPTs collaboratively designed two lessons on a predefined topic, with a pedagogical focus and contextual constraints, one in a laboratory format and the other in a full classroom format. They then taught their peers, and analyzed their teaching by watching a videotape of their lesson and engaging in pedagogical discussions with their peers led by the instructors after their lesson. The design phase of the lessons provided many opportunities for student-initiated help seeking as well as instructorinitiated scaffolding in the face-to-face consultation meetings and online discussions in a designated forum on the course website (see Fig. 1 for the structure of a full project). We discuss the rationale and details of the design, illustrate the radical change in the PPTs' lessons plans and its relationship to the particular scaffolding elsewhere [21]. The course is still taught by the first author, with a few additional adjustments inspired by the insights from this first iteration, and with a different TA who is also an experienced in-service physics teacher, whose main responsibility is to guide the preservice teachers in the design of the lessons.

\section{METHOD}

\section{A. Participants}

The participants were 28 PPTs, composed of graduates of the faculty of physics $(N=8)$, graduates of "physics dominated" engineering faculties $(N=16)$, undergraduate students from engineering faculties $(N=2)$, and undergraduate students studying for a B.Sc. in Science Education $(N=2)$. Many participants also had a Master's degree $(N=10)$. Many $(N=10)$ were working in industry while they took the course and were considering a career change to education. Others had just started to work as teachers (for most of them this was their second career) of physics $(N=9)$, mathematics $(N=1)$, or middle school science $(N=1)$, with the proviso that they complete their certification within two years. They ranged in age from 22 to 61 with a median age of 35 .

\section{B. Data collection}

The data included the videotapes of all consultation meetings ( $\sim 30$ min each, 40 meetings), the various drafts of the lesson plans the PPTs posted on the course website, and the instructors' written feedback on the group forum (see Fig. 1).

\section{Working assumption}

As mentioned in the introduction, the specific specialized knowledge, practices, and beliefs that were brought into the open and articulated during the interaction between the instructors and the PPTs over the evolving lesson plans depend closely on the goals and scope of the course, and the instructors' perception of what counts as a good physics lesson. Our working hypothesis in this study was that not all the related features of high quality physics teaching are transparent to novice and preservice teachers, so they may not always be aware that they should ask for assistance. Thus, when searching for instances in which tacit professional knowledge, practices, and beliefs were brought into the open during the interaction between the instructors with the PPTs on their evolving lesson plans, we examined both student-initiated and instructor-initiated concerns, guidance, and support.

\section{Analysis}

The analysis took a grounded theory approach. The grounded theory approach to qualitative analysis has evolved and taken different forms since it was first proposed in the late 1960s [30]. The chapter on Grounded Theory in the Handbook of Qualitative Research [31] characterizes these forms along a spectrum that ranges from objectivist grounded theory which is based on the positivist tradition, and constructivist grounded theory, which is based on the interpretive tradition. The current study falls near the constructivist end of this spectrum, as discussed in detail at the end of this section.

In the first phase of the analysis the second author thematically divided the recordings of the consultation meetings and the written feedback from the instructors into segments that captured either challenges that were raised by the PPTs or various scaffoldings suggested by the instructors. In many cases contextual descriptors were added to the segments, such as the specific part of the assignment the PPTs were discussing, reference to the artifact the interlocutors were relating to, etc. The database included 780 segments after the first phase of the analysis. Each segment represented an expression of a particular challenge or difficulty. The drafts of the lesson plans were used to further contextualize each segment as well as document the evolution of the lesson plans. see [21]

The second phase of the analysis was an iterative exhaustive bottom-up classification aimed at unpacking the specialized knowledge, practices and beliefs that were brought into the open during the interactions between the instructors and the PPTs over the evolving lesson plans. As stated in the introduction, the instructors' perception of what counts as a "good lesson" and the constraining features of the course affected the content of these interactions.

First, the segments were classified by the second author into categories that shared similar attributes. Since the segmentation was thematic, each segment could be classified into several categories, where different words and expressions in the segments highlighted different aspects of the PPT's knowledge (or lack thereof). Second, we both discussed a set of randomized examples for each category, 
assigned a label that characterized the category, and formulated a definition that articulated its meaning. Third, the second author rechecked the entire classification, and highlighted conflicts in the classification according to the updated definitions. Fourth, we both discussed the problematic segments and then added or deleted classifications, or refined their definitions (more often). Such refinements often required an operationalization of the definition [32]. This involved listing particular descriptors of segments (explicit and contextual) that determined whether it could be coded into that particular category. In some cases, when encountered with repeated confusions, the operationalization also included descriptors that suggested when a segment does not belong to the category. Examples are provided in Sec. IV. During this phase the authors aggregated and reaggregated categories into clusters and subclusters, where this clustering had an indicative contribution. This process required several iterations.

When we both fully agreed on the hierarchical classification that emerged from the analysis, specific attention was directed to segments that were classified into more than one category. These segments were reexamined to determine whether they could be divided into smaller segments that could be classified into separate categories. A clear-cut division between categories was not always possible and more than half of the segments remained classified in more than one category (see examples in the next section). The difficulty of empirically discerning where one category of professional knowledge in use differs from another from teachers' discourse has been reported by other researchers as well. For example, Ball et al. [7] wrote that this difficulty "affects the precision (or lack thereof) of our definitions" (p. 403), and Krepf et al. [11] argued that this difficulty is actually empirical evidence of Shulman's hypothesis that PCK is an "amalgam of content and pedagogy." [33].

At the end of this phase the dataset was divided into 846 segments. A few segments (27) included discussions that referenced issues that were irrelevant to this analysis, such as personal issues, personal conflicts between group members, or questions and answers about course management and responsibilities. Segments that included these topics were eliminated from the dataset (27). The final classification presented here relates to the remaining 819 segments, which were eventually classified into a hierarchical thematic categorization composed of 23 categories organized in clusters and subclusters that reflect the nature and structure of knowledge, practices, and beliefs that were brought into the open during the interactions between the instructors and the preservice teachers over the evolving lesson plans (i.e., first research question). Of these discussions, some of the segments were initiated by the PPTs, and some by the instructors. We examine this differentiation in detail in Sec. IV.

To explore the second research question; i.e., the extent to which this knowledge, practices, and beliefs were grounded in the discipline (physics), each segment was coded for whether the manifestation of knowledge, practice, or belief in the segment was explicitly contextualized in the disciplinary content of instruction (physics). For example, while designing a lesson that aimed to engage students in modeling simple harmonic motion, Maya (pseudonym) suggested using a computer simulation of a pendulum followed by a demonstration of a pendulum. Joseph (pseudonym), her peer collaborator on this assignment, asked "When you say a 'demonstration' you mean an experiment?" The instructor explained that the term demonstration refers to instances in which the teacher demonstrates the phenomenon and the students observe, while the term experiment refers to students' hand-on laboratory activity (segment 465, group 6 , 2st meeting). This differentiation is not unique to the teaching of physics and is common to biology and chemistry; thus this segment was not coded as contextualized in the discipline taught. Section IV discusses multiple examples of segments that were coded as contextualized in the physics content in question.

The process of coding and categorizing is central to both the objectivist and constructivist grounded theory approach. During this process, categories are formulated and integrated into a "tree" that conceptually link them and form the basis of the developing theory. The formulation of categories and their integration into a conceptual hierarchical tree arises from multiple and various comparisons [30,34,35]: comparison across different participants, comparison of the same individuals but in different points in time, comparing across incidents, comparing coded data and category definitions, and comparing categories. The categories and the connections between them shape the developing analytic framework. Note that the literature review on specialized knowledge for teaching that was provided in the conceptual framework section was done at an advanced stage of the study, and served as background ideas that informed the overall research problem; it was not imposed on the emergent categorization at any phase of the analysis.

The researchers were also the designers and the instructors of the course. This makes them also participants in the study, and thus may constitute a sever limitation with regard to the generalizability of the findings. At the extreme objectivist end of the spectrum of grounded theory [36] this feature may create a bias that cannot be eliminated. However, at the constructivist end of the spectrum [35] this is not a problem as long the nature, structure, and values of the context are clearly specified. Specifically, a constructivist approach acknowledges that both data and analysis are inherently created from the shared experience of the researchers and the participants of the study, and a key underlying assumption is that the analysis is contextually situated in time, place, culture, and situation [35]. To give readers a sense of the extent to which the specific instructors' (and authors') guidance impacted the categories observed, 
Sec. IV presents not only the number of segments that were coded into each category but also the percentage of coded segments that reflect PPT-initiated guidance and instructorinitiated guidance, and we discuss the implications of this differentiation. We discuss the generalizability and implications of the findings, in view of the limitation stated above, in Sec. V.

\section{FINDINGS}

Out of the 819 segments that composed the dataset, 808 were coded as being explicitly contextualized in the instruction of physics. This section presents the emerging classification of these 808 segments. The emergent classification, presented in Fig. 2, yielded three overarching clusters: Disciplinary content (201), Curriculum and standards (185), and Teaching (701). Each cluster is discussed in the following sections separately. Each cluster is divided into several subclusters and categories. Each category label reflects a different kind of knowledge, practice, or belief that was brought into the open through PPT-initiated requests for guidance, or instructor-initiated guidance while the PPTs worked on their lesson plans. For each basic category we present the number of coded segments, the percentage of PPT-initiated, and instructor-initiated coded segments, an operationalized definition of the category, and an illustrative example.

\section{A. Disciplinary content (201)}

Categories in this cluster represent expressions and discussions that refer to knowledge and beliefs about the scientific content brought up during the design of the lessons.

\section{Understanding of the scientific concepts and ideas to be taught (83: P-42\%, I-58\%)}

This category represents discussion and guidance on the knowledge of physics shared by others who know and use physics. It is similar to Ball's [7] category of common content knowledge in mathematics, and corresponds to Grossman's [4] notion of substantive knowledge. Operationally, segments coded in this category included discourse that represented the PPTs' difficulties in understanding the physics they were supposed to teach, such as explicit requests for clarifications, and incorrect or confused use of concepts, which are often expressed by many students of physics as well.

Consider, for example, the following excerpt (Segment 689, group 9, 2nd consultation meeting) drawn from a discussion about a demonstration. The PPTs were planning to use a Slinky to demonstrate the basic concepts of waves, and were playing with it during the meeting. The instructor noticed that they did not differentiate between the propagating and returning waves, and showed them that the
Slinky behaved differently depending on whether the end was loose or fixed. The PPTs were surprised:

Oren: The fact that it (the Slinky with the loose end) does not transverse the phase (of the returning wave, as we saw in the case of the fixed end), it does not make sense! Ins.: But it is a loose end. This is what happens in a flute, a saxophone, it's a standing wave in (a string with) a loose end.

Oren: What is the meaning of all this?

Oren's difficulty in this example had to do with understanding the content, not the pedagogy. In the next turns the instructor briefly explained the phenomenon of standing waves in a string, and sent the PPTs to further review the topic, although it was not the focus of the lesson.

\section{Familiarity and correct operation of scientific instruments and devices (112: P-40\%, I-60\%)}

Segments in this category represent discussions and guidance concerning the understanding of the function, as well as how to correctly operate measuring instruments, experimental apparatuses, and run demonstrations and simulations used for the instruction of physics. Note that segments that were coded into this category do not represent considerations of the pedagogical affordances and constraints of these instruments and devices, which belong to a different category. Since this knowledge is mostly needed for purposes of teaching, this category corresponds to Ball's [7] category of specialized content knowledge.

The following example (segment 399, group 6, written feedback) is drawn from a discussion on the course website on the 2nd draft of a lesson plan. The group planned to engage the students in an experiment on Newton's laws of motion. The contextual constraint of the assignment was that there were no computer-based sensors. The PPTs decided to use the acceleration sensor on their mobile phones, with a cart, pulley, and different weights as their apparatus. The instructor noticed that the PPTs needed guidance in choosing the appropriate components (in this case weights) for the experimental apparatus, since they were not familiar with the equipment.

Ins.: Watch out that if you are working with the PASCO carts, the weights should be smaller; otherwise, the acceleration will be too large to (get) a good measurement. We have (smaller) weights in the lab that can provide good resolution.

\section{Beliefs and opinions about physics (11: P-55\%, I-45\%)}

Segments in this category correspond to discussions in which the PPTs expressed their beliefs and opinions about physics (as opposed to beliefs and opinions about what and how to teach physics) and the instructors' responses to 


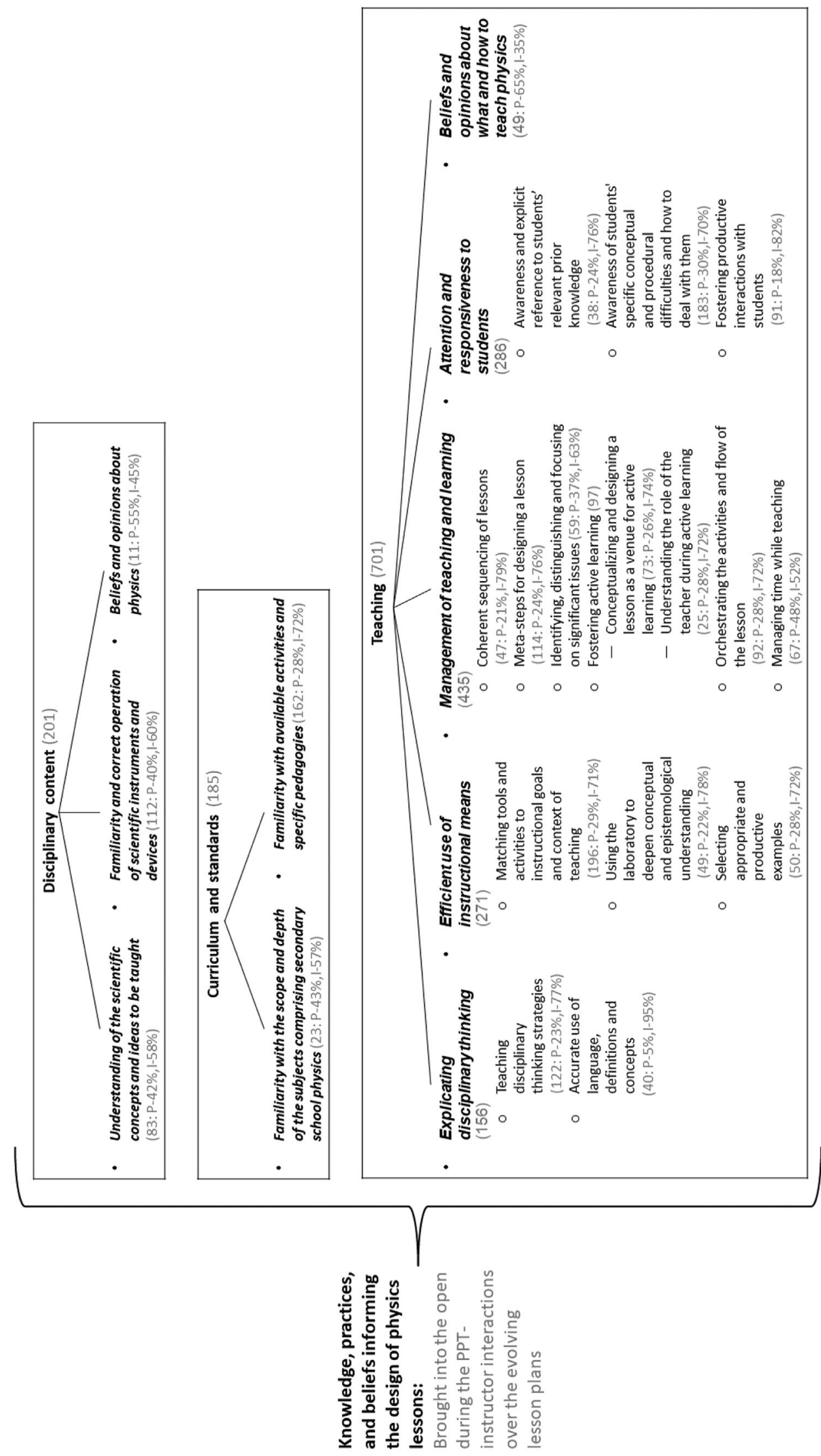

FIG. 2. The emergent classification of knowledge, practices, and beliefs informing the design of a physics lesson, which were brought into the open during the PPT-instructor interactions over the evolving lesson plans. Numbers represent the number of segments that were classified into a specific cluster, subcluster, or category. Note that a segment could be classified into more than one category. Percentages represent the fraction of PPT-initiated (P) or instructor-initiated (I) segments that were coded under each lowest-level category. 
these comments. These segments mainly included concerns that physics principles work primarily in theory, not in reallife situations. This category corresponds to Grossman's [4] notion of subject-matter beliefs, but in the specific context of physics.

The following illustrative example (segment 53, group 1, 2nd consultation meeting) is drawn from the discussion on the 2nd draft of a lesson plan. The PPTs were planning a laboratory session on the interference and diffraction of mechanical waves. They wanted to engage their students in an experiment on interference in a ripple tank. The problem was that there was only one ripple tank in the laboratory. The instructor suggested that each group of students in the class would (i) take a photograph of an interference pattern in the tank for a different frequency of the oscillator, (ii) analyze the photograph in Tracker [37] and find the wavelength, (iii) share the result with all the other groups to collaboratively build a graph of the wavelength vs the frequency, and (iv) calculate the velocity of the propagating waves in the ripple tank from the slope. One of the PPTs was concerned (and this is where the segment starts):

Nibal: It (the suggested plan) depends so much on their (the students in the class) results...we might not get one velocity ...

Nibal, a newly graduated medical engineer who joined the program, knew that in theory the velocity of water waves at a given depth does not change with the frequency (she had explicitly stated this $2.5 \mathrm{~min}$ before the above excerpt). However, she was not sure that this is what would happen in a real measurement situation; i.e., that the "physics theory" would "work" in class. Interestingly, quite a few PPTs expressed this type of concern. Note that while such concerns may at first glance be considered a belief about how to teach physics, they actually reflect a (dis)belief about the applicability of the laws of physics to real-life situations (i.e., beliefs and opinions about physics per se). Categories related to beliefs were the only categories in which the number of studentinitiated segments exceeded the number of instructorinitiated segments.

\section{B. Curriculum and standards (185)}

Categories in this cluster represent expressions and discussions of what should be formally taught in secondary school physics and the available curricular materials.

\section{Familiarity with the scope and depth of the subjects comprising secondary school physics (23: P-43\%, I-57\%)}

Segments in this category represent PPT or instructorinitiated support about standards and requirements (e.g., what a student should know to pass the matriculation exam in physics). This corresponds to the category of knowledge of science curricula of Magnusson et al. [5]; specifically, knowledge about the goals and objectives of teaching science, and their category of knowledge of assessment.

For example, a PPT whose group was preparing an introductory lesson on standing waves asked (segment 607, group 8,1 st consultation meeting):

Aviva: So we shouldn't address the sine and cosine (when we teach standing waves) /.../? Do the students need it (meaning: is this kind of derivation required on the matriculation exam?)

Ins.: Students don't need this (for the matriculation exam).

Aviva was specifically inquiring about the required mandatory depth and scope of the content to be learned.

\section{Familiarity with available activities and specific pedagogies (162: P-28\%, I-72\%)}

Segments in this category concern familiarity with activities, experiments, visualizations, and other ways to teach a given topic in physics that were mentioned as possible resources for the lesson by the PPTs or the instructors during the meeting or in written correspondence. This category corresponds to the category of knowledge of science curricula of Magnusson et al. [5]; namely, familiarity with specific curriculum materials, and Ball's [7] category of knowledge of content and curriculum. It does not include considerations of the pedagogical affordance of each resource, only awareness of its existence. For example, consider an excerpt below from a discussion about a 1st draft of a lesson plan about wave interference (segment 30 , group 1,1 st consultation meeting):

Ins.: Are you familiar with the PhET website [38]? There is a great simulation there (of waves in a pool).

The instructor introduced the PPTs to a simulation that could provide an effective visualization for their lesson, and a resource (PhET website [38]) for other visualizations in the future. After the turn above, the instructor presented the simulation, and discussed its instructional affordances with the PPTs, but that part was assigned to a different category (Matching tools and activities to instructional goals and context of teaching-see IV C 2 a below).

The relatively higher instructor-initiated segments that were coded under "familiarity with available activities and specific pedagogies," compared to the coding of the previous categories, is not that surprising when considering the instructors' rich experience as physics teachers and curriculum developers.

\section{Teaching (701)}

This is the largest cluster in the dataset. It is divided into four subclusters and one independent category. Each subcluster represents a different facet of knowledge, 
practices, and beliefs that are materialized in the teaching of physics at the secondary school level, as they came to bear in the interactions of the instructors and the PPTs over the evolving lesson plans. These include explicating disciplinary thinking (156), productive and efficient use of instructional means (272), management of teaching and learning (434), attention and responsiveness to students (288), and beliefs and opinions about what and how to teach physics (49).

\section{Explicating disciplinary thinking (156)}

Categories in this subcluster represent expressions and discussions that reveal the guidance the PPTs needed to become aware and learn how to unpack and make features of particular disciplinary content, practice, and epistemology visible and learnable by students. This subcluster corresponds to Ball's [7] category of specialized content knowledge for teaching, and to some extent as well to Grossman's [4] category of syntactic content knowledge. The difference is in the focus on the specific enactment of this knowledge in teaching (i.e., practice) rather than the knowledge per se, and the articulation of practices which the subcategories provide. Two distinct facets of this enactment (i.e., categories) were identified.

a.Teaching disciplinary thinking strategies (122: P-23\%, $I-77 \%$ ).-Segments in this category mainly represent instructors' initiated guidance on how to explicate disciplinary heuristics and strategies such as how to approach problem solving, modeling, estimation, etc. This category corresponds closely to Ball's [7] category of specialized content knowledge for teaching; however, the focus on the enactment (i.e., how to unpack this knowledge and make it learnable by the students) corresponds to some extent to the category of knowledge of instructional strategies of Magnusson et al. [5]. Operationally this means that either the instructors or the PPTs were verbalizing the structure and process of the strategy or heuristic.

The following example (segment 79, group 2, 1st consultation meeting) is drawn from a discussion of a lesson plan on Newton's second law of motion that was scheduled to take place towards the end of the teaching of this topic, and aimed to deepen students' understanding and provide tools for complex problem solving. The 1st draft of the lesson plan was composed of a list of 4 problems that the PPTs were planning to solve with the students during the lesson (45 minutes) and solutions for these problems. The instructor was concerned:

Ins.: Do you (plan to) teach a strategy on how to approach a problem? /.../When you (the PPT) solve a problem on the whiteboard, you should explain to the students how you approach it and the steps you employ to solve it /.../ (in the next turns the instructor provides an example of how he does it, describing a kind of road map that he builds with the students: choose a body for a free-body diagram, identify all the external forces that are exerted on this body, etc.)

The instructor sensed that the PPTs' focus was on solving specific problems instead of teaching how to approach any problem that involves force and motion considerations, and systematically use the principles they learned to solve it, and thus responded accordingly.

The proportion of instructor-initiated segments in this category (77\%) corresponds to most of the categories under the teaching cluster $(\sim 70 \%-80 \%$ of the segments, apart from very few exceptions which will be discussed specifically, see Fig. 2.) This proportion is higher than the categories under the "disciplinary content cluster", or the category of "familiarity with the scope and depth of the subjects comprising secondary school physics" under the "curriculum and standards cluster" (60\%-70\%). We interpret this as evidence that it is easier for novice teachers to realize that they do not understand the content, compared to noticing tacit aspects of teaching.

b.Accurate use of language, definitions and concepts (40: P-5\%, I-95\%).- -Segments in this category mainly represent instructors' initiated guidance in helping the PPTs to adhere their use of concepts with the concepts' precise definitions, or correcting inaccurate and misleading uses of language with regard to scientific concepts, ideas, and procedures taught. Note that the segments that were classified into this category do not necessarily reflect incorrect knowledge, but rather inaccurate use of language that could occasionally be used by people who know physics (making it inapplicable to category A1), but should not be used by people who teach physics, in line with Ball's [7] differentiation between common content knowledge and specialized content knowledge for teaching.

The example (segment 212, group 3, written feedback) is drawn from the instructors' written comment on the 3rd draft of the lesson plan. The PPTs were asked to design a laboratory lesson in which the students were required to plan an experiment that demonstrated Newton's second law. The PPTs wrote a laboratory manual in which they referred to the mass as the "unknown." The instructor was concerned with the language:

Ins.: You should be more precise. The dependent variable in the experiment is the acceleration. The independent variable is the pulling/pushing force. There is another independent variable - the mass. In order to examine the influence of the pulling force, we set the mass to a fixed value. We call this process the "separation of variables". Referring to the mass as the "unknown" is inaccurate. The mass is an independent variable that we set as the constant. 
The PPTs knew that they could infer the value of the mass from the experimental results using Newton's second law as the reference model. This is probably why they referred to the mass as "the unknown". However, "the unknown" is an imprecise scientific descriptor for the mass. This segment was also classified into the previous category (Teaching disciplinary thinking strategies). The instructor interfered since she noticed that the PPTs' imprecise use of language masked an important principle: the essence of separating variables.

Almost all the segments that were coded in this category (95\%) were instructor initiated. We consider that this is a result of the nature of this category. In most cases PPTs cannot independently determine when they use language, definition, or concepts inaccurately. Despite this, the fact that 40 segments were coded in this category suggests that this was an aspect of teaching that both instructors valued. Also fostering conceptual clarity was an explicit focus of the course.

\section{Efficient use of instructional means (271)}

Categories in this subcluster represent expressions and discussions that reflect the guidance the PPTs needed in choosing, matching, and adapting available instructional representations and activities to the educational goals and environmental context in which the lesson was going to be taught (e.g., number and level of the students, the goals of the lesson, available equipment, etc.). This subcluster of categories elaborates and expands Ball's [7] category of knowledge of content and teaching, and the category of knowledge of instructional strategies of Magnusson et al. [5], and articulates them as forms of practice.

a.Matching tools and activities to instructional goals and context of teaching (196: P-29\%, I-71\%).--Segments in this category express the guidance the PPTs needed to productively match the instrument or activity they wanted to employ to the instructional goals and the lesson format (class or lab, number of students, etc.). It corresponds to Ball's [7] category of knowledge of content and teaching, and the category of knowledge of instructional strategies of Magnusson et al. [5], but also to Grossman's [4] notion of knowledge of context. However, it describes enactment rather than knowledge. Note that this category is different than the category "familiarity with available activities and specific pedagogies" (see Sec. IV B 2). Markers for inclusion in this category include explicit referencing and considerations of at least one of the following regarding a tool or activity: the goals of the lesson, specific pedagogical features and attributes of the tool or activity, the setting of the lesson (laboratory or regular classroom), and the target audience (age, prior knowledge, liking, etc.)

The following example is drawn from a discussion on the 1 st draft of the lesson plan (segment 628, group 9, 1st consultation meeting). The goal of the lesson was to engage the students in an experiment that quantitatively illustrated (a) the conservation of energy, and (b) the transformation between different forms of energy. The PPTs described the experiment that they were planning to do and the instructor interrupted:

\section{Eli: If we will do the experiment with horizontal (spring)... \\ Ins.: But then you will miss out on the opportunity to include (also) gravitational energy. The idea is to cover all the types of mechanical energy the students encountered in one experiment. That is the power of this experiment (vertical spring; measuring kinetic, elastic and gravitational energy change), and with a very simple tool-the Tracker [37] (video analysis software)...}

The instructor noticed that the PPTs had missed a central pedagogical affordance of the experiment that was highly supportive of the instructional goal of the lesson.

b.Using the laboratory to deepen conceptual and epistemological understanding (49: P-22\%, I-78\%).Segments in this category mainly represent instructors' initiated guidance that aimed to teach the PPTs how to use learners' hands-on activities in the laboratory to leverage and support epistemological and conceptual understanding of physics. It articulates a manifestation of Ball's [7] category of knowledge of content and teaching, and the category of knowledge of instructional strategies of Magnusson et al. [5], grounds them in the context of teaching physics, and describes them in terms of enactment (practice rather than knowledge per se).

The example is drawn from the instructor's written feedback on the 1st draft of the lesson plan that was uploaded to the course website. The assignment was to plan and engage the learners in an experiment that quantitatively illustrated Newton's second law. The PPTs submitted an initial plan for an experiment, and wrote that "We will conduct a concluding discussion about the experiment" without any further elaboration. The instructor commented (segment 401, group 6, written feedback):

Ins.: Here are some questions worth discussing with the learners: which parameters did we set as fixed in the experiment and which of them did we change? What is the dependent variable and what is the independent variable? What changes would we make if we wanted to verify the acceleration as a function of the system mass? (What are the) reasons for measurement errors and how can we estimate their size? etc.

The instructor sensed that the PPTs did not elaborate on features of the experiment in the concluding discussion because they saw the experiment as a means to an end, 
namely, "validating" Newton's second law. She assumed that they wrote that they would have a concluding discussion merely because they knew that they were expected to have one. She suspected that they were not aware of the epistemological ideas that can be gleaned from the experiment, or how to structure the activity and the ensuing discussion in a way that would bring these ideas into the open. Many groups manifested similar difficulties with regard to the work in the laboratory. Given the explication of disciplinary heuristics and strategies with regard to the specific experiment in the instructor's feedback, this segment was also classified into the category "Teaching disciplinary thinking strategies" (see Sec. IV C 1 a).

c.Selecting appropriate and productive examples (50: $P-28 \%, I-72 \%)$. - Segments in this category represent the PPTs' difficulty to select examples (not tools or activities which belong to a different category) that illustrate the concepts and ideas the lesson aimed to convey, and the related guidance that was provided. As in the previous two categories, the connection to Ball's [7] category of knowledge of content and teaching, and the category of knowledge of instructional strategy of Magnusson et al. [5] is straightforward, and further relates it to examples, a specific kind of instructional representation, and the enactment of this knowledge. Discourse in segments that were coded into this category included discussions about the selection or rejection of examples and the reasons for these decisions.

The following example is a synopsis of a lengthy written discussion on the 3 rd draft in which the instructor explained to the PPTs why a central example in their lesson plan did not serve the goal of the lesson (segment 163, group 2, written feedback).

The group was preparing a laboratory lesson that used an existing laboratory manual. The manual shows students how to prepare an Excel simulation that numerically solves the equations for the motion of a stellar body that free falls towards the Earth in a straight line from a very large distance, changing its acceleration as it falls. The PPTs wanted to connect the laboratory to real life and decided to add a paper and pencil problem about a communication satellite that orbits the Earth. The instructor responded that the idea of linking the activity in the laboratory to a relevant context was commendable but that the specific example did not illustrate the numerical problem in question. She explained that the simulation solves the problem of a body moving toward the Earth in a straight line perpendicular to the Earth's surface, but that a communication satellite cannot orbit the Earth without a tangential velocity, and often stays at the same height relative to Earth. She suggested that the PPTs try to find a more appropriate example.

The instructor noticed that the example the PPTs chose did not emphasize the central conceptual features of the hands-on activity in the laboratory. The PPTs were familiar with the general pedagogical principle of the importance of connecting classroom activities to real-life situations. The guidance they needed was how to productively apply this principle to the practice of teaching a particular topic in a particular discipline. Part of this difficulty may also have stemmed from a shallow understanding of the content in question (i.e., the essence of the motion of satellites); hence we also classified this segment into the category "Understanding of the scientific concepts and ideas to be taught."

\section{Management of teaching and learning (435)}

This large subcluster includes six categories that represent different facets of managing and facilitating students' learning at different temporal scales, as manifested in the design of a lesson. Categories in this subcluster do not easily map onto one particular category of professional knowledge for teaching. Rather most can be seen as simultaneously informed by several categories of professional knowledge for teaching reported in the literature. Most categories in this subcluster are more closely related to "know how" than to "know that," and thus can be considered as articulated practices rather than knowledge per se. We believe that these categories emerged from the analysis since we were trying to infer professional knowledge of teaching from the authentic practice of designing a lesson which took place in a unique naturalistic setting that invited an explication of practice (consultation meetings and written feedback on evolving drafts of lesson plans).

a.Coherent sequencing of lessons (47: P-21\%, I-79\%).Segments in this category represent PPT-initiated and instructor-initiated guidance in how to coherently connect the specific lesson they prepared to the overall sequence of lessons in the unit or topic (e.g., impulse and momentum). Operationally, segments in this category represent at least one of the following: explicit considerations of how the lesson relates to the overall picture of the topic the PPTs or the curriculum aim to convey, discussion of the organization, sequence and relations of the lesson to the content in other lessons. It does not include the sequencing of activities and content in the specific lesson, which were assigned to a different category (see "Orchestrating the activities and flow of the lesson" below).

The following example (segment 1, group 1, 1st consultation meeting) is drawn from a discussion with a group of PPTs who were given the assignment to design a lesson that aimed to deepen the students' conceptual understanding of the work and energy theorem. The assignment required the PPTs to employ the pedagogy of learning from mistakes [39]. One of the PPTs asked

Nibal: Can we assume that they (the learners) have already learned about kinetic energy and work? 
Ins.: It is you (i.e., the teacher) who determines what they already know and what they do not. /.../ When you map a lesson over a unit (a required part of the assignment), you determine where it is (with respect to the unit), generally and specifically/..../ Think about what you taught them in the last lesson l.../

Nibal was asking about the learners' prior knowledge, and her question was also classified into "Awareness and explicit reference to learners' relevant prior knowledge" (IV C 4 a, see below). However, the instructor's response was coded into the current category. His response suggested that he noticed that Nibal was referring to concepts that are part of the unit the lesson is part of, and that he suspected that her difficulty was actually in temporally placing the lesson within the sequence of lessons that composed the unit. To productively sequence the lesson, teachers must activate and coordinate different forms of knowledge. Knowing how to productively address this practice is an additional form of knowledge, and the instructor suggested a strategy to address this challenge.

b.Meta-steps in designing a lesson (114: P-24\%, I-76\%).Segments in this category mainly represent instructorinitiated advice as to what the PPTs should (or should not) do in the process of planning and designing the lesson (i.e., articulated practice). These included helping the PPTs to regulate the stress involved, mainly due to conflicts over time management, often having to remind the PPTs to predefine the purpose of the lesson and constantly verify the extent to which the lesson plan adhered to it, often having to remind the PPTs to allocate time to self-experience a new experiment or demonstration they planned to use in class, remind the PPTs that they should think ahead about questions for the discussion, how they wanted to summarize the lesson, etc.

For example (segment 337, group 5, 2nd consultation meeting):

Doron: Do you think we need more questions (on the worksheet) or is this (what we did so far) enough?

Ins.: You should prepare your (class) discussion. (That is,) in addition to responding to what you see (i.e., students' work), I would relate to g, /.../(to) how to find a resultant acceleration when the coordinate system is shifted, and prepare the discussion. What I mean is that I wouldn't let it (the discussion) fly on its own (power), I would think ahead about the issues that are important to mention.

The instructor noticed that the PPTs were only concerned about the preparation of the worksheet, and did not understand that similar efforts should be devoted to the preparation of a discussion and summary that are crucial for a strong wrap up of the take-home message from the lesson.
c.Identifying, distinguishing, and focusing on significant issues (59: P-37\%, I-63\%).-Segments in this category represent the guidance the PPTs needed in identifying and emphasizing the main ideas the lesson aimed to convey on the one hand, and in focusing on these main goals instead of deviating from them. While this category is loosely connected to the knowledge of instructional strategies of Magnusson et al. [5] and Ball's [7] specialized content knowledge, in our view, it explicates the practice of facilitating and nurturing knowledge integration [40].

Consider the following example (segment 382, group 5, written feedback). The assignment was to plan a lesson that engaged the learners in complex problem solving that involved either the work and energy and/or impulse and momentum theorems, and aimed to provide the learners with means to approach these problems. Implementing guidance from the instructors, the PPTs designed a worksheet in the 2nd draft that aimed to explicate and guide the learners in ways to break down a complex problem into a series of simpler and solvable subproblems by identifying the physics principles that characterized each subproblem in a table. The instructor read the worksheet and commented on one feature in the group forum:

Ins.: It seems to me that the column "equations" (in the worksheet) is unnecessary... (Instead,) I would add a column of "(what is) the relevant system". I.../ the worksheet that you have prepared is appropriate because it (makes the students) look at the problem conceptually. The goal (of your worksheet) is to give the students an overview (of the main principles) and only then direct them to delve into the details... (In your worksheet) the "equation" column belongs to the details, not to the overview...

This segment was classified as "Identifying, distinguishing, and focusing on significant issues" since the instructor noticed that the PPTs had forgotten to highlight an extremely important feature in the process of problem solving; i.e., guiding learners to identify the physical system in question, rather than overstating the "plug and chug" process of calculation. This segment was also classified under "Teaching disciplinary thinking strategies" (C1a) since the identification of the physics system in question is an important heuristic in physics problem solving. It was also coded as "Matching tools and activities to instructional goals and context of teaching" (IV C 2 a), since the instructor complemented the PPTs on the fact that the worksheet they designed served the goals of the lesson well.

d.Fostering active learning (97).-This subcluster of categories most likely emerged because of the overarching requirement of all the lesson plans. We insisted that each lesson have a segment in which all the learners 
were actively involved and did something other than listening. Complying with this demand was quite challenging for the PPTs, and required a great deal of PPTinitiated or instructor-initiated guidance. Generally speaking, two forms of guidance were needed, each of which highlights a different facet of knowing how to design and foster active learning. We refer to each as a separate subcategory.

Conceptualizing and designing a lesson as a venue for active learning (73: $P-26 \%, I-74 \%$ )

Segments in this subcategory represent knowledge about how to design and/or implement an activity in which all the learners must be engaged. In a sense this category corresponds to the category of knowledge of instructional strategies of Magnusson et al. [5], but is far more specific in its focus (active learning) and its language of enactment. Segments that were classified into this category discussed specific activities that can engage all the students in the class.

The following example is drawn from a discussion with a group of PPTs whose assignment was to prepare a lesson on simple harmonic motion that aimed to engage the students in an activity that fostered the development of a deeper understanding of the phenomenon. The PPTs' initial plan was to lecture about the features of simple harmonic motion, and then engage the students in an unspecified inquiry of a PhET simulation [38]. The instructor tried to push them in a different direction (segment 426, group 6, 1st consultation meeting):

Ins.: What do you think about (engaging the students in) inventing a problem (on simple harmonic motion)?

Maya: When will we have time to do this?

Ins.: /.../ Instead of telling the students what the significant variables are (refers to their plan to lecture on these with regard to a pendulum), instead of leading a discussion (refers to their completely unspecified use of "whole class discussion" in their draft).

The instructor interfered since he felt that the PPTs were clueless about how to prepare an activity that engaged the students in deeper thinking about the physical aspects of the phenomenon.

Understanding the role of the teacher during active learning (25: P-28\%,I-72\%)

Segments in this category represent PPT-initiated and instructor-initiated guidance geared towards an understanding of what a teacher should do when the students are working on a task during the lesson and thus the teacher is not lecturing. Again, there is an implicit connection to Magnusson's category of knowledge of instructional strategies, but this category entails a far more detailed articulation of a specific strategy, or even a habit of mind. [8]

The illustrative example is drawn from discussion about the 2nd draft (segment 156, group 2, 2nd consultation meeting). The group's assignment was to teach a laboratory lesson in which students use Excel to create a numerical simulation of a stellar body that free falls towards the Earth from a very large distance, changing its acceleration as it falls. They planned to lecture on a pre-prepared Excel simulation that they wanted to project on the whiteboard. The instructor tried to convince them instead to let the students work in pairs on the computer, and guide them in building the simulation. One of the PPTs (Lily) suddenly realized that this would be feasible. She started to explain her ideas but was soon interrupted by her partner (Tuvia).

Lily: ...in class, we will generate the simulation. We (the PPTs) will give the students the skeleton (of the Excel file) and they will enter the formulas by themselves.

Tuvia: Each group makes its own simulation?

Lily: Yes.

Tuvia: Then what does the teacher do (during the lesson)?

The instructor understood from Tuvia's reaction that he should pause and explicitly discuss what he would have done as a teacher if his students were working on this particular simulation and in general.

e. Orchestrating the activities and flow of the lesson (92: $P-28 \%, \quad I-72 \%)$.- Segments in this category represent PPT-initiated and instructor-initiated considerations regarding the flow and connections between instructional activities, tasks and representations and their specific implementation within one lesson. It does not include considerations of time management which are captured by the next category (IV C $3 \mathrm{f}$ ), or the connections between several lessons in a unit which is captured by a previous category in this cluster (Coherent sequencing of lessons, IV C 3 a). To some extent this category corresponds to the category of knowledge of instructional strategies of Magnusson at al. [5], or Ball's [7] category of content and teaching, but it is described at a far more specific level of competency and does so in terms of practice.

The following example (segment 110, group 2, written feedback) is drawn from the instructor's written comments on the 3rd draft of a lesson plan on Newton's second law that focused on strategies for complex problem solving. The instructor noticed that although the PPTs had prepared a worksheet, its implementation in the lesson was not specified and, in fact, their plan was to merely solve the problems from the worksheet on the whiteboard. The instructor assumed that the PPTs had no idea how to do this and offered an alternative implementation with a rationale:

Ins.: Giving the students time to work on a worksheet, discussing it in groups and then with the whole class, is not a waste of lesson time. If you orchestrate the lesson well, then you can go through the worksheet: each student works alone (on the problem on the worksheet), 
then, perhaps discuss the problem with a partner, and then you (the PPTs) sum up the solutions on the whiteboard and address difficulties that you spotted (during the students' work). You only move on to the next problem after that (on the worksheet).

The segment above was also classified into the category "conceptualizing and designing a lesson as a venue for active learning" (see IV C $3 \mathrm{~d}$ above), and "awareness of students' specific conceptual and procedural difficulties and how to deal with them" (see IV C $4 \mathrm{~b}$ below).

f.Managing time while teaching (67: P-48\%, I-52\%).Segments in this category mainly represent guidance that was triggered when the PPTs did not correctly evaluate the time needed for a given activity, could have used it more efficiently, or forgot to allocate time for specific activities. In terms of knowledge, this involves being able to correctly gauge the time required for a specific activity.

For example, when referring to the 2nd draft of a lessonplan in which the PPTs planned to engage the students in a relatively complex analysis of experimental results related to energy transformation, the instructor wrote (segment 665, group 9, written feedback):

Ins.: I hope that you plan to leave 5-10 minutes to discuss the graphs the students drew.

Note that the excerpt above not only concerns "generic" efficient management of time, but a consideration of what the time slot should be allocated for. In addition, in contrast to other categories in the teaching cluster, here about half of the segments were PPT initiated. We consider that this is because time management often bothers novice teachers who struggle to "cover" the planned curriculum.

\section{Attention and responsiveness to students (286)}

This subcluster represents categories that highlight the knowledge, practice, and habits of mind required for the design of lessons that anticipate and deliberately take students' backgrounds, difficulties and diversities into account. The categories in this subcluster cohere with Ball's [7] category of knowledge of content and students, the category of knowledge of students' understanding of science of Magnusson et al. [5], and Grossman's [4] very broad category of knowledge and beliefs about context. However, the categories that make up this cluster articulate specific knowledge and habits of mind that inform the design of physics lessons, and reflect thinking ahead about and responding to students' interests and needs (i.e., articulated practices).

a.Awareness and explicit reference to students' relevant prior knowledge (38: P-24\%, I-76\%).-Segments in this category mainly represent instructor-initiated support that aims to activate and enhance the PPTs' awareness of the prerequisite knowledge to understanding what they plan to teach, and whether this is indeed something that the learners already know. PPT- initiated help seeking in this category was expressed when the PPTs identified prerequisite knowledge and consulted with the instructors as to whether they could assume its existence or how to help learners recall it.

The following illustrative excerpt is drawn from a discussion about a lesson plan in which the PPTs were planning to engage their students in an experiment on Newton's second law using computerized sensors (segment 174, group 3, 1st consultation meeting). The instructor had to explicitly draw the PPTs' attention to the implicit assumptions in their plan about their peers' (i.e., the students in the lesson) prior knowledge:

Ins.: You should map the skills. Which skills (required for the experiment) the students (are already) familiar with, and which not? For example, they already know how to use a computerized lab, right?

Note that the latter question was a rhetorical one since the consultation meeting took place immediately after a lesson led by another group which had taught their peers how to use the computerized sensors. The point is that when the PPTs wrote the draft they were unaware of this. The segment above was also classified under "Meta-steps in designing a lesson" (C3b), due to the suggestion to "map" the learners' skills.

b.Awareness of students' specific conceptual and procedural difficulties and how to deal with them (183: $P-30 \%, I-70 \%)$.- Segments in this category concern the awareness of, and knowledge about, students' conceptual, procedural, or other difficulties related to the instruction of particular topics or procedures, as well as various ways to deal with these difficulties.

For example, consider a group of PPTs who designed a lesson that focused on problem solving of complex problems related to the work and energy theorems, and/ or impulse and momentum theorems. In the first consultation meeting (segment 343, group 5, 1st consultation meeting), one of the PPTs, who had started to teach part time parallel to the course, said,

Doron: Students have a lot of problems (while working) with parameters (referring to his K11 students' preference to substitute values into the parameters at every step of the solution, instead of solving the problem with parameters and only then substituting values.)

This segment was coded to this category because Doron was specifically addressing a difficulty his K11 students have. As the conversations developed it became clear that he was not sure how to act upon this 
knowledge in his lesson plan. In other segments he specifically consulted with the instructor on how to address it. For example, he wondered whether phrasing the problem in parameters would be better or worse than phrasing it with values (i.e., the initial velocity is $V_{1}$ vs the initial velocity is $10 \mathrm{~m} / \mathrm{sec}$ ) and whether it would be more productive in focusing the students' attention on the problem-solving strategy he was going to teach. The latter issue also falls under the next category (c). There is no single answer to this question since the specific answer depends on the context and goal of the lesson, and this question sparked further discussion.

c.Fostering productive interactions with students (91: $P-18 \%, \quad I-82 \%)$. - Segments in this category covered knowledge and understanding how to design a lesson for productive interactions with the students, such as providing correct comprehensible instructions, predicting and preparing responses to students' mistakes, how to open the door to creative ideas, etc.

The following example (segment 360, group 5, 1st consultation meeting) is drawn from the same meeting that we mentioned in the previous category (teaching students how to approach complex problems that involve energy and momentum considerations). The PPTs designed a worksheet that prompted the learners to divide a complex problem into a series of simpler subproblems. The learners were asked to fill in a table, in which each row represented a given subproblem the learners had to define. Each column of the table represented an attribute of a subproblem (e.g., the relevant physical principle) which the students had to fill in. Doron, the PPT mentioned above, was not sure whether and how he should design the worksheet to deal with student-initiated solutions that differed from the one he anticipated.

Doron: If I think that the complex problem has six stages, should I leave (in the table) six rows, and force them to divide the problem into six stages, or should I tell them (to divide it into) as many stages as they like? Ins.: I would give seven rows (in the table), and write in the instructions "You don't have to fill in all the rows and if you need, add more rows."

The instructor's answer shows how a small change in the design of the worksheet may allow, and even invite, different ways of thinking.

\section{Beliefs and opinions about what and how to teach physics (49: P-65\%,I-35\%)}

Segments in this category concern beliefs about teaching physics (e.g., how a topic should be taught), physics teachers (e.g., how a physics teacher should behave), and physics learners (e.g., what they are capable of, and what their interests are). This category corresponds to some extent to Grossman's [4] very broad categories of pedagogical knowledge and beliefs, and knowledge and beliefs about context, but it is far more localized and grounded in the teaching of the discipline (i.e., physics).

The following example is drawn from a group of PPTs that designed a lesson aimed at engaging learners in developing a mathematical model of motion in constant acceleration. In the following excerpt (segment 256, group 4, 2nd consultation meeting) two of the PPTs explicitly expressed the belief that high school physics is not "real physics" given the students' limited background in mathematics.

Moran: /.../ when you teach high school physics you bend the physics and the mathematics, so they fit the students' knowledge.

Michal: (in high-school) You use a lot of "hand waving" (instead of 'real' physics).

Note that this belief refers directly to the teaching of physics, and is not related to physics per se. The instructors needed to devote a great deal of time and effort in convincing and demonstrating to the PPTs that "serious physics" can be taught in high school, and that the level of mathematics employed is far from being the only yardstick for doing "serious physics." Note that this category, as well as the category of beliefs and opinions about physics were the only categories in which the percentage of PPT-initiated segments exceeded the percentage of instructor-initiated segments. We consider that this result may stem from the fact that the instructors designed the course, including the initial assignments for the design of each lesson. Thus, the PPTs' beliefs and opinions about physics and about physics teaching were implicitly challenged more frequently.

\section{SUMMARY AND DISCUSSION}

This section is organized around the two research questions that framed the study.

\section{A. The first research question}

The first research question inquired what elements of knowledge, practices, and beliefs were brought into the open and articulated while the instructors guided and supported the preservice teachers in the design of the physics lessons that the preservice teachers were asked to teach during the course. Figure 2 summarizes the emergent classification that resulted from this study. Within the situative and contextual features of the study, this classification articulates knowledge, practice, and beliefs that inform and guide the design of physics lessons that provide in-depth treatment of concepts, procedures, practices, and epistemological aspects of physics in an engaging and meaningful way for students, and foster active learning. The first cluster highlights aspects related to the disciplinary content that was being taught. Categories articulated 
in this cluster suggest that physics teachers need to understand the scientific concepts and ideas they teach, become familiar with and know how to correctly operate relevant scientific instruments and devices in the school laboratory and beyond, and hold productive beliefs about physics. The second cluster shows that physics teachers need to know the curriculum and standards related to their teaching, which includes the scope and depth of the subjects comprising secondary school physics (1st category), and available activities and specific pedagogies (2nd category).

The largest and most significant cluster was the third (teaching), which captures a significant portion of the art and crafts of teaching physics. In our view, the first four subclusters delineate some of the core practices that comprise the teaching of physics. The first core practice (subcluster) is the ability and tendency to explicate disciplinary thinking. Our analysis divided this practice into two subpractices (categories): (i) the explications of disciplinary thinking strategies, and (ii) the use of precise, accurate and consistent language, definitions, and concepts. The second subcluster represents efficient use of instructional means. Our categorization articulated this core practice into three subpractices (categories): (i) matching tools and activities to instructional goals and the context of teaching, (ii) using the laboratory to deepen conceptual and epistemological understanding, and (iii) selecting appropriate and productive examples. The third subcluster represents a germane core practice: the management of teaching and learning. Our analysis articulated this core practice into the following six subpractices (categories): (i) sequencing lessons in a coherent manner, (ii) following the metasteps of designing a physics lesson, (iii) identifying, distinguishing and focusing on significant issues, (iv) conceptualizing and designing a lesson as a venue for active learning, and effectively conducting oneself as a teacher in these instances, (v) orchestrating the activities and flow of the lesson, and (vi) managing time while teaching. The fourth subcluster represents the core-practice of attending and responding to students. Our categorization articulated this core practice into sub-practices and knowledge (categories): (i) awareness and explicit reference to students' relevant prior knowledge (knowledge and practice), (ii) awareness of students' specific conceptual and procedural difficulties and how to deal with them (knowledge and practice), (iii) fostering productive interactions with students (practice). The fifth branch of the teaching cluster is an independent category that reflects knowledge that constantly influences the aforementioned practices; namely, the teacher's beliefs and opinions about teaching physics. Note that the practices articulated above are highly informed by the teacher's knowledge (content and beliefs).

The variety of models of PCK that we reviewed in the conceptual framework section [3-5,7,33] differ in terms of their structure and components. While there are many similarities, the scope and components of each model are not identical, and there are aspects of PCK that are represented in some models but not in others. This study was limited to the design of physics lessons, within the constraints of the goals and scope of a particular methods for teaching physics course and the instructors' perspective of what counts as a good physics lesson. Despite these limitations, the analysis not only provides additional evidence for the entire spectrum of previously described aspects of PCK while grounding them in the teaching of physics, but goes beyond it. The third cluster in particular (teaching, see Fig. 2) articulates many core practices that are essential to the planning and teaching of high quality physics lessons at the $\mathrm{K}-12$ level (and in our view in more advanced classes as well). It articulates and unpacks these core practices into some of the central practices that comprise them, and the knowledge they require, and grounds them in the discipline that is being taught. The course provided opportunities for the PPTs to engage in an inquiry into their own lesson designs. The structured interactions with the instructors that were integral to the course forced the instructors to externalize and verbalize many of the tacit considerations which they employ when they teach physics.

While limited solely to the design of a lesson plan, and situated within particular methods for teaching physics course, to the best of our knowledge, this is the first attempt to suggest a model of the professional knowledge, practices, and beliefs about teaching that is specifically grounded in the instruction of physics. Given the situational nature of our inquiry, we do not presume that the emergent model presented in Fig. 2 captures the entire spectrum of specialized knowledge, practice, and beliefs that encompass high quality instruction of physics. That said, we believe that the emergent model captures a significant portion of professional knowledge and practices that are crucial for high quality physics teaching. Our analysis also corresponds and contributes to recent calls to structure teacher education around core practices of teaching $[2,15,16]$ by articulating practices that are deeply grounded in the instruction of physics.

More than half of the segments were classified into more than one category. This finding is consistent with Shulman's theoretical conceptualization of PCK as an "amalgam of content and pedagogy" [33] as well as other empirical attempts to define the structure and nature of PCK $[7,11]$. Designing a conceptually and epistemologically deep physics lesson that engages students in the learning process in a personally meaningful way is a complex and challenging task. Teachers need to capitalize on and coordinate a range of knowledge, skills, and resources, and address many interconnected issues. For instance, as our findings show, teachers need to define their disciplinary and pedagogical goals, make sure that they understand the scientific content, map it on the curriculum, choose appropriate instructional representations and 
activities, and often invent new or adapt existing activities and representations, learn to operate measurement instruments, test the experiment or simulation, consider students' difficulties and interests, prepare the interaction with the students, and orchestrate the lesson so the goals will be achieved in the allocated time. This complexity makes it very difficult to assign segments of natural language into separate categories. Sometimes the PPTs' discourse initially addressed more than one aspect of knowledge, practice, or beliefs. At other times, the PPTs expressed a struggle in one specific facet of knowledge, practice, or beliefs, and the instructor responded by structuring or problematizing the task by addressing other aspects [21].

\section{Limitations and contributions}

The emergent classification of knowledge, practices, and beliefs that were brought into the open and articulated during the interaction between the instructors and the PPTs on the evolving lesson plans (see Fig. 2) is an outcome of an analysis that adheres to a constructivist approach to grounded theory [31,35]. Clearly, the emergent model of professional knowledge, practice, and beliefs that inform the design of physics lessons (Fig. 2) which resulted from the study is inherently limited by the goals and scope of the course in which the data were collected, and the instructors' perception of what counts as high quality teaching of physics.

As mentioned in the descriptions of the study and the course, Methods for Teaching Physics 1 focuses on conceptual clarity, problem solving, and active and meaningful learning. Scientific inquiry and argumentation are a prime focus of a different course in the program. How might this constraint, for example, affect the content and structure of the specialized knowledge, practices, and beliefs that were brought into the open? Specifically, how and to what extent do we think the emergent model would have changed if we had collected our data in a course centered on scientific inquiry and argumentation? We anticipate that the category "beliefs and opinions about what and how to teach physics" would have been significantly enriched since this kind of teaching challenges most PPTs former experiences as students. However, in our view, the most dramatic effect would have been in the subcluster of "explicating disciplinary thinking." We believe that more categories would have been identified and aggregated under this cluster in a course that dealt mainly with inquiry and argumentation in physics. In particular, the first category (teaching disciplinary thinking strategies) could have been further refined and probably split into several subcategories that captured practices that explicate features such as differentiating evidence from claims or generating and testing models. In the same manner, however, we believe that if we would have conducted the study in that course, we might have only marginally characterized some of the features revealed by the present study.
The emergent classification presented in Fig. 2 inherently resonates with the instructors' perspective of what counts as a good physics lesson, since they designed the course, and the data are drawn from their interactions with the PPTs. As our analysis clearly shows, there were far more segments that reflected instructor-initiated support than segments that reflected PPT-initiated support in most categories. As indicated in Fig. 2, this effect was stronger the more the category was related to pedagogical content knowledge rather than pure content knowledge. This observation supports our initial working assumption that not all the related features of high quality physics teaching are transparent to novice and preservice teachers, so they may not always be aware that they should ask for assistance. The only categories in which the number of coded PPT-initiated segments exceeded instructor-initiated segments were the categories that concerned beliefs and opinions about physics and about teaching physics. Since the instructors also designed the course and the assignments that initiated the design of each lesson plan, it is likely that the PPTs' beliefs and opinions about physics and about physics teaching were implicitly challenged more frequently than the instructors' beliefs. It is worth recalling that the course instructors' view "good physics lessons" as lessons that provide in-depth treatment of concepts, procedures, practices, and epistemological aspects of physics, and do so in an engaging and meaningful way for the students, while fostering active learning. We acknowledge that the perception of experienced physics teachers can vary considerably as to the specifics of what counts as a good physics lesson. However, we believe that no teacher would strongly object to the instructors' perception as described here.

The aforementioned limitations constitute the inherent constraints associated with applying constructivist grounded theory. Nevertheless, we feel that despite these limitations, the power of this approach in uncovering and unpacking tacit knowledge, practices, and beliefs is overwhelming. Given the fact that the emergent model corresponded to all the features that were identified in previous attempts to unpack professional knowledge for teaching and add to them, we think that the emergent model provides a reasonable first approximation for specialized knowledge, practices, and beliefs that inform the design of high quality physics lessons.

\section{B. The second research question}

The second research question inquired to what extent the knowledge, practices and beliefs that were brought into the open during the interaction between the instructors and the PPTs on the design of the lesson were grounded in the discipline. While we expected that a significant portion of the segments would be explicitly grounded in the physics content that was being taught, we were surprised at the extent of this grounding. In the physics education 
community there is a deep concern that the main scope of educational preparation of future physics teachers takes place in schools of education in a disciplinary-generic manner [20,41,42]. Aside from a few exceptions [19,43], even when schools of education offer some disciplinarybased educational courses, biology, chemistry, and physics are considered as one discipline, namely, "science." The detailed examples that we provided for each category highlight the fundamental contextualization in the discipline of the knowledge, practices, and beliefs that were brought into the open while helping preservice teachers design good lessons in physics. In our view, teacher educators who are not experienced physics educators would not have noticed a significant portion of the PPTs' challenges that were discussed in the examples for each category.

Out of the 819 segments that comprised the dataset, 808 were coded as explicitly contextualized in the disciplinary content (i.e., physics). Note that the core of most of the issues discussed in these segments could be rephrased, on a more general level, as reflecting generic educational principles. However, as our examples clearly show, what the preservice teachers needed help with was not familiarity with the generic principles, but in developing an understanding of when and how to apply these principles to the instruction of the specific discipline-physics in our case. For example, no one would question the importance of unpacking ways of thinking and knowing that characterize a discipline. However, the PPTs were not struggling with this general idea, but rather with the actual unpacking of specific content, and how to structure specific instructional activities to reflect it.

Challenges like this can only be addressed through disciplinary-based teacher education. We do not make the claim that one cannot create productive interdisciplinary connections in teaching or benefit from (some) general educational courses in teacher training. Nevertheless, one should not expect that ideas learned in a generic course will spontaneously transfer to the practice of teaching a specific discipline. Many studies of transfer of learning in science and mathematics emphasize the centrality of the context of learning to the tendency to transfer [44-46]; hence, why should we expect that learning in teacher education would be different?
[1] L. Darling-Hammond and J. D. Bransford, Preparing Teachers for a Changing World: What Teachers Should Learn and Be Able to Do (Jossey-Bass, 2007).

[2] D. L. Ball and F. M. Forzani, The work of teaching and the challenge for teacher education, J. Teach. Educ. 60, 497 (2009).

[3] L. S. Shulman, Those who understand: Knowledge growth in teaching, Educ. Res. 15, 4 (1986).

[4] P. L. Grossman, The Making of a Teacher: Teacher Knowledge and Teacher Education (Teachers College Press, New York, 1990).

[5] S. Magnusson, J. Krajcik, H. Borko, and K. Tobin, Nature, sources, and development of pedagogical content knowledge for science teaching, in Examining Pedagogical Content Knowledge, edited by J. Gess-Newsome and N. G. Lederman (Kluwer Academic, Dordrecht, 1999), pp. 95-132.

[6] P. Friedrichsen, J. H. Van Driel, and S. K. Abell, Taking a closer look at science teaching orientations, Sci. Educ. 95, 358 (2011).

[7] D. L. Ball, M. H. Thames, and G. Phelps, Content knowledge for teaching what makes it special?, J. Teach. Educ. 59, 389 (2008).

[8] E. Etkina, B. Gregorcic, and S. Vokos, Organizing physics teacher professional education around productive habit development: A way to meet reform challenges, Phys. Rev. Phys. Educ. Res. 13, 010107 (2017).

[9] A. Berry, P. Friedrichsen, and J. Loughran, Re-examining Pedagogical Content Knowledge in Science Education (Routledge, New York, 2015).
[10] S. K. Abell, Research on science teacher knowledge, in Handbook of Research on Science Education, edited by S. K. Abell and N.G. Lederman (Lawrence Erlbaum Associates, Hillsdale, NJ, 2007), pp. 1105-1149.

[11] M. Krepf, W. Plöger, D. Scholl, and A. Seifert, Pedagogical content knowledge of experts and novices-what knowledge do they activate when analyzing science lessons?, J. Res. Sci. Teach. 55, 44 (2018).

[12] M. M. Keller, K. Neumann, and H. E. Fischer, The impact of physics teachers' pedagogical content knowledge and motivation on students' achievement and interest, J. Res. Sci. Teach. 54, 586 (2017).

[13] E. A. Davis, D. Petish, and J. Smithey, Challenges new science teachers face, Rev. Educ. Res. 76, 607 (2006).

[14] J. A. Luft, S. L. Dubois, R. S. Nixon, and B. K. Campbell, Supporting newly hired teachers of science: Attaining teacher professional standards, Stud. Sci. Educ. 51, 1 (2015).

[15] P. Grossman, K. Hammerness, and M. McDonald, Redefining teaching, re-imagining teacher education, Teach. Teach. Educ. 15, 273 (2009).

[16] M. McDonald, E. Kazemi, and S. S. Kavanagh, Core practices and pedagogies of teacher education, J. Teach. Educ. 64, 378 (2013).

[17] L. C. McDermott, A perspective on teacher preparation in physics and other sciences: The need for special science courses for teachers, Am. J. Phys. 58, 734 (1990).

[18] A. B. Arons and L. C. McDermott, Teachers of physics in our schools, Am. J. Phys. 60, 103 (1992). 
[19] E. Etkina, Pedagogical content knowledge and preparation of high school physics teachers, Phys. Rev. ST Phys. Educ. Res. 6, 020110 (2010).

[20] V. Otero, N. Finkelstein, R. Mccray, and S. Pollock, Who is responsible for preparing science teachers?, Science $\mathbf{3 1 3}$, 445 (2006).

[21] S. Kapon and A. Merzel, Pre-service physics teachers' learning from guided cycles of pedagogical design and teaching of lessons., Phys. Educ. 54, 015026 (2019).

[22] A. Collins, J. S. Brown, and S. E. Newman, Cognitive apprenticeship: Teaching the crafts of reading, writing, and mathematics, in Cognition and Instruction: Issues and Agendas, edited by L. B. Resnick (Lawrence Eribaum Associates, Hillsdale, NJ, 1989).

[23] M. Gamoran Sherin and E. van Es, Effects of video club participation on teachers' professional vision, J. Teach. Educ. 60, 20 (2009).

[24] E. Etkina, D. Gitomer, C. Iaconangelo, G. Phelps, L. Seeley, and S. Vokos Design of an assessment to probe teachers' content knowledge for teaching: An example from energy in high school physics, Phys. Rev. Phys. Educ. Res. 14, 010127 (2018).

[25] Physics Teacher Education at the Technion-Israel Institute of Technology, http://edu.faculty-ms.technion.ac.il/ r_and_d/physics-education/?lang=en.

[26] J. Benton-Kupper, The microteaching experience: Student perspectives, Education 121, 830 (2001).

[27] E. A. Davis, M. Kloser, A. Wells, M. Windschitl, J. Carlson, and J.-C. Marino Teaching the practice of leading sense-making discussions in science: Science teacher educators using rehearsals, J. Sci. Teach. Educ. 28, 275 (2017).

[28] V. Kind, Pedagogical content knowledge in science education: Perspectives and potential for progress, Stud. Sci. Educ. 45, 169 (2009).

[29] J. S. Krajcik and P. C. Blumenfeld, Project-based learning, in The Cambridge Handbook of the Learning Sciences, edited by R. K. Sawyer (Cambridge University Press, Cambridge, England, 2006), p. 317-334.

[30] B. G. Glaser and A. L. Strauss, The Discovery of Grounded Theory: Strategies for Qualitative Research (Aldine de Gruyter, New York, 1967).
[31] K. Charmaz, Grounded theory: Objectivist and constructivist methods, in Handbook of Qualitative Research, edited by N.K. Denzin and Y.S. Lincoln (SAGE Publications, Thousand Oaks, CA, 2000), pp. 509-535.

[32] L. M. Top, S. A. Schoonraad, and V. K. Otero, Development of pedagogical knowledge among learning assistants, Int. J. STEM Educ. 5, 1 (2018).

[33] L.S. Shulman, Knowledge and teaching: Foundations of the new reform, Harv. Educ. Rev. 57, 1 (1987).

[34] J. Corbing and A. L. Strauss, Basics of Qualitative Research: Techniques and Procedures for Developing Grounded Theory (SAGE Publications, Thousand Oaks, CA, 2015).

[35] K. Charmaz, Constructing Grounded Theory: A Practical Guide through Qualitative Analysis (SAGE Publications, Thousand Oaks, CA, 2006).

[36] B. G. Glaser, Basics of Grounded Theory Analysis: Emergence vs. Forcing (Sociology Press, Mill Valley, CA, 1992).

[37] D. Brown, Tracker-Video Analysis and Modeling tool (2018), https://physlets.org/tracker/.

[38] University of Colorado Boulder. PhET-Interactive Simulations, https://phet.colorado.edu/.

[39] E. Yerushalmi and C. Polingher, Guiding students to learn from mistakes, Phys. Educ. 41, 532 (2006).

[40] M. C. Linn and B.-S. Eylon, Science Learning and Instruction (Routledge, New York, 2011).

[41] V. Otero, S. Pollock, and N. Finkelstein, A physics department's role in preparing physics teachers: The Colorado learning assistant model, Am. J. Phys. 78, 1218 (2010).

[42] D. E. Meltzer and V. Otero, Transforming the preparation of physics teachers, Am. J. Phys. 82, 633 (2014).

[43] Physics Education at the Technion (2015), https://edu .faculty-ms.technion.ac.il/r_and_d/physics-education/? lang=en (Accessed: 21st December 2017).

[44] J. F. Wagner, Transfer in pieces, Cognit. Instr. 24, 1 (2006).

[45] J.F. Wagner, A transfer-in-pieces consideration of the perception of structure in the transfer of learning, J. Learn. Sci. 19, 443 (2010).

[46] R. A. Engle, Framing interactions to foster generative learning: A situative explanation of transfer in a community of learners classroom, J. Learn. Sci. 15, 451 (2006). 